OPEN ACCESS

Edited by:

Hui Chen,

Zhejiang University, China

Reviewed by:

Patricia E. Román,

Loyola University Andalusia, Spain

Naveen Kashyap,

Indian Institute of Technology

Guwahati, India

*Correspondence:

Maria Soledad Beato msol@usal.es

†These authors have contributed equally to this work

Specialty section: This article was submitted to

Cognitive Science,

a section of the journal

Frontiers in Psychology

Received: 27 January 2021

Accepted: 18 March 2021

Published: 09 April 2021

Citation:

Suarez M and Beato MS (2021) The Role of Language Proficiency in False Memory: A Mini Review.

Front. Psychol. 12:659434. doi: 10.3389/fpsyg.2021.659434

\section{The Role of Language Proficiency in False Memory: A Mini Review}

\author{
Mar Suarez ${ }^{\dagger}$ and Maria Soledad Beato*t \\ Faculty of Psychology, University of Salamanca, Salamanca, Spain
}

Memory errors and, specifically, false memories in the Deese/Roediger-McDermott paradigm have been extensively studied in the past decades. Most studies have investigated false memory in monolinguals' native or first language (L1), but interest has also grown in examining false memories in participants' second language (L2) with different proficiency levels. The main purpose of this manuscript is to review the current state of knowledge on the role of language proficiency on false memories when participants encode and retrieve information in the same language. To do so, a systematic literature search was conducted, and the available studies were reviewed. These studies differed in, for example, age, language proficiency, or material characteristics, including both high and low associative strength lists, and they reported different results. In this review, we attempted to make sense of the apparently contradictory results by carefully identifying participants' language dominance and L2 proficiency. Specifically, the results indicated that, first, people are more prone to produce false memories in their dominant than in their non-dominant language. This result generalizes to lists with high and low associative strength, as well as to participants of different ages. Second, false memories do not differ between two languages when speakers are equally proficient in both languages. Finally, highly proficient $L 2$ speakers produce more false memories in their $L 2$ than speakers with lower $L 2$ proficiency. The results of this review will be considered in the light of the theoretical frameworks of false memories and bilingual language processing.

Keywords: false memories, false recognition, DRM paradigm, bilingualism, language proficiency

\section{INTRODUCTION}

In recent years, there has been considerable interest in investigating the malleable nature of human memory. Memory is a reconstructive process that is prone to errors (Kolodner, 1983) and this fact has implications in real-world settings such as eyewitness testimonies (Aizpurua et al., 2009; Havard and Memon, 2013; Loftus, 2018) or the clinical practice (Otgaar et al., 2017; Turk et al., 2020). Among all the potential memory errors, a substantial body of research has focused on understanding false memories, that is, memories for events that did not occur. Specifically, in this review we will focus on a particular type of false memory: the associative memory illusion (see Gallo, 2006, 2010 for review).

False memories have been mostly investigated in monolinguals of very diverse languages, such as Germanic languages (e.g., English, Stadler et al., 1999; Dutch, Van Damme and d'Ydewalle, 2009), Romance languages (e.g., Portuguese, Albuquerque, 2005; Spanish, Beato and Díez, 2011; French, Dubuisson et al., 2012) and Slavic languages (e.g., Polish, Ulatowska and Olszewska, 2013). 
Even non-Indo-European languages have been employed to study the associative memory illusion (e.g., Chinese, Chen et al., 2008; Japanese, Kawasaki and Yama, 2006), with a robust false memory effect in all of them. However, false memories have not only been studied in first languages (L1), but also in second languages (L2) with different proficiency levels (e.g., Anastasi et al., 2005; Arndt and Beato, 2017; Beato and Arndt, 2021).

It is important to note that language proficiency may vary with language usage and experience, and, therefore, it is not a constant feature. Bilingualism and monolingualism would be the two ends of a continuum with no clear division between them due to a lack of consensus on the definition of bilingualism (Edwards, 2004) and a high variability in its measurement (Surrain and Luk, 2019). In this review, our purpose is not to define bilingualism, but rather to study false memories across the proficiency continuum on participants with some knowledge of a second language.

Different questions have been investigated in the literature regarding false memories in various languages. First, some research has focused on false memories when languages are switched between encoding and retrieval (i.e., between-language false memory) (see Graves and Altarriba, 2014 for review). Second, another line of research has been interested in whether language and memory processes differ between bilinguals and monolinguals (e.g., Bialystok et al., 2020). Third, and the aim of this review, increasing interest has been centered on whether language proficiency influenced false memories when participants encode and retrieve information in the same language (i.e., within-language false memory). To this aim, we reviewed all the available articles investigating this topic that emerged from a systematic literature search. In particular, our goals were to (1) examine false recognition in the L1 versus L2, centering our attention on language dominance and L2 proficiency, and (2) discuss the findings in terms of the theoretical frameworks.

\section{FALSE MEMORIES: THE DRM PARADIGM}

One of the most widely used paradigms to study false memories is the Deese/Roediger-McDermott (DRM) paradigm (Deese, 1959; Roediger and McDermott, 1995). In this paradigm participants study lists of words associated to a non-studied word (i.e., critical lure). For example, participants study the words hot, ice, snow, warm, winter, and weather, all of them associated to the critical lure cold, based on free association norms (e.g., Nelson et al., 1998). At the test, participants often falsely recall and/or recognize the critical lures as studied items.

The DRM paradigm has been extensively used to study the mechanisms underlying false memories by manipulating variables such as backward and forward associative strength (e.g., Brainerd and Wright, 2005; Arndt, 2012, 2015; Beato and Arndt, 2014, 2017), presentation rate (e.g., Seamon et al., 1998; Smith and Kimball, 2012; Sadler et al., 2018), number of words associated to the critical lure (e.g., Arndt, 2010; Flegal and Reuter-Lorenz, 2014), presentation modality (e.g., Mao et al., 2010; Boldini et al., 2013), retrieval time (e.g., Giammattei and Arndt, 2012; Carneiro et al., 2014), attentional demands (e.g., Pérez-Mata et al., 2002; Otgaar et al., 2012), distinctive encoding (e.g., Huff et al., 2015, 2020), warning instructions (e.g., Watson et al., 2004; Carneiro and Fernandez, 2010; Coane et al., 2016), identifiability of the critical lure (e.g., Neuschatz et al., 2003; Carneiro et al., 2009; Beato and Cadavid, 2016), or emotional valence (e.g., Bookbinder and Brainerd, 2016; Hellenthal et al., 2019; Chang et al., 2020), among many others. All these experimental manipulations confirmed the robustness of this paradigm to produce false memories.

Furthermore, the DRM paradigm has also been employed to study false memories in different clinical populations such as patients with schizophrenia (e.g., Bhatt et al., 2010; Favre et al., 2020), Alzheimer's disease (e.g., Malone et al., 2019; Howe and Akhtar, 2020), or autism spectrum disorder (e.g., Wojcik et al., 2018). Additionally, it has been used throughout development in children (e.g., Carneiro et al., 2007; Brainerd et al., 2008; Knott et al., 2011), and older adults (e.g., McCabe et al., 2009; Devitt and Schacter, 2016).

Not only behavioral research has been conducted on false memories. Some efforts have also been made to identify the neural correlates of false memories (see Schacter and Slotnick, 2004 for review) using techniques such as functional magnetic resonance imaging (e.g., Abe et al., 2013), event-related potentials (e.g., Curran et al., 2001; Beato et al., 2012; Cadavid and Beato, 2016), near infrared spectroscopy (e.g., Kubota et al., 2006), positron emission tomography (Schacter et al., 1996), or transcranial direct current stimulation (e.g., Díez et al., 2017).

The two main theoretical explanations of the false memory effect in the DRM paradigm are the fuzzy-trace theory (FFT; Reyna and Brainerd, 1995; Brainerd and Reyna, 2002) and the activation-monitoring framework (AMF; Roediger et al., 2001) (see also global matching models, Arndt and Hirshman, 1998). According to FFT, two types of information are encoded during the study of the DRM lists: verbatim traces (i.e., perceptual features of the event) and gist traces (i.e., meaningbased information of the event). If gist memory traces are retrieved, false memories are more likely to occur because critical lures tend to match the meaning information extracted from the list. Therefore, the critical lure's meaning would be familiar. That familiarity triggered by the critical lure might be countervailed by retrieving verbatim traces of the studied items, a process referred to as recollection rejection (Brainerd et al., 2003), that would reduce false memories. For its part, AMF suggests that false memories are produced by the combination of activation and monitoring processes. When a DRM list is studied these words are activated and the activation is spread throughout the semantic network to associatively related words, namely, the critical lure, increasing the likelihood to produce false memories. In order to counteract that activation, monitoring processes might be engaged. Monitoring processes are defined as decision processes that use different types of information to determine the source of the activation and so false memories can be reduced (Gallo, 2006). As will be discussed later, both theories (i.e., FFT and AMF) could potentially explain the results of the present review, but in slightly different ways. 


\section{TWO LANGUAGES IN ONE BRAIN}

A central question in bilingual research is how two languages are represented in one brain (Heredia and Brown, 2006). Various models have been developed to seek an answer (e.g., bilingual interactive activation model, Dijkstra and Van Heuven, 2002; inhibitory control model, Green, 1998; distributed feature model, Van Hell and De Groot, 1998; revised hierarchical model, Kroll and Stewart, 1994) and, despite differing in the exact nature of L1 and L2 representations, these models share a consensual view about two assumptions relevant for the present review. First, both languages access a shared conceptual system (Francis, 1999, 2020; Francis et al., 2019) and, second, associations between word forms and their concepts are stronger in L1 than in L2 (e.g., Gollan et al., 2008). To further elaborate on these ideas, the revised hierarchical model $(\mathrm{RHM})^{1}$, referred above, will be considered.

The RHM assumes two different levels of representation, the lexical and conceptual level, with independent lexical representations for each language and a shared conceptual store. First, at the lexical level, although both languages are stored independently, they are interconnected with stronger connections from L2 to L1 than from L1 to L2 (Kroll et al., 2002). The explanation is found in the fact that the $L 2$ is acquired by creating links between L2 words and the correspondent L1 translation at the lexical level, leading to stronger connection from L2 to L1. By contrast, links from L1 to L2 are weaker due to a lack of translation practice in that direction (Kroll and Stewart, 1994). Second, at the conceptual level, the links between words and concepts (i.e., conceptual links) are assumed to be stronger in L1 than L2. This means that the concept store is fully activated quicker from L1 than from L2 lexical representations. Nonetheless, once L2 learners become more proficient, the conceptual links from L2 words to the concepts become stronger (Perea et al., 2008).

Although the RHM interprets that the first language acquired (L1) is the dominant language, it is noteworthy that bilingual memory is a dynamic system influenced by language usage (Heredia and Altarriba, 2001). Thus, as Heredia (1997) suggested, the L1 might lose strength while the L2 might become the dominant language as a function of exposure, hence the L1 and L2 should be interpreted as the dominant and nondominant language, respectively, disregarding which language was learned first.

\section{FALSE MEMORIES AND LANGUAGE PROFICIENCY}

In this review, we investigated the role of language proficiency in false memory when information was encoded and retrieved in L1 versus L2 (i.e., within-language conditions) ${ }^{2}$. To this end, we identified participants' dominant and non-dominant language and their L2-proficiency level. This was crucial to

\footnotetext{
${ }^{1}$ As some concerns have been raised regarding the RHM (e.g., Brysbaert and Duyck, 2010), see Kroll et al. (2010) for a critical review and assessment of this model.

${ }^{2}$ Note that some reviewed studies also included other experimental conditions.
}

understand and discuss the different results, but it was not an easy task. Specifically, regarding language dominance, sometimes it was difficult to identify which language was dominant (not necessarily the L1) based on the available information. Furthermore, regarding language proficiency, it was difficult to compare this variable across studies due to, first, different facets of bilingual experience being reported (e.g., usage or years of academic training; see Surrain and Luk, 2019). Second, there were differences in language proficiency (see Table 1), with some studies employing highly proficient bilinguals that used both languages in everyday life (e.g., Cabeza and Lennartson, 2005), while others included participants whose only L2 experience was in a classroom setting (e.g., Arndt and Beato, 2017). Third, although most of the studies included young adults ( $M=24.04$ years across experiments), children were also tested (Howe et al., 2008), possibly leading to age related differences in L1 and L2 proficiency.

Focusing now on the results, when comparing false memory in the L1 and L2, some studies found L1 > L2, others L1 < L2, or even, L1 = L2 (see Table 1). That is, although, to our knowledge, only eight works have investigated this topic, all possible results have been reported. However, as referred above, language dominance can make sense of the apparently contradictory results. In other words, if we compare false memory in the dominant and non-dominant languages, instead of considering the order of language acquisition (i.e., L1 versus L2), consistent conclusions can be drawn. To further elaborate on this idea, the three patterns of results observed in the reviewed studies will be explained below.

First, beginning with the most common result, the studies that found significantly higher false recognition in L1 than L2 (Anastasi et al., 2005, Experiments 3 and 4; Sahlin et al., 2005; Howe et al., 2008; Arndt and Beato, 2017; Beato and Arndt, 2021) reported that the dominant and non-dominant language were the L1 and L2, respectively. That is, false recognition was higher in the dominant than in the non-dominant language in these studies. Kawasaki-Miyaji et al. (2003) and Marmolejo et al. (2009) seemingly point in the same direction, with higher false recognition in L1 (dominant) than in L2 (non-dominant) (0.71 versus 0.62 , and 0.80 versus 0.73 , respectively), although they did not directly test this comparison statistically.

This pattern of results has also been found in 6-, 8-, and 12year-old children (Howe et al., 2008). This study not only showed that false recognition increased with age in both languages, but also that all age groups were more likely to produce false recognition in L1 (dominant) than in L2 (non-dominant). Furthermore, the effect of language dominance on false memory was obtained in most of the studies using DRM lists strongly related to the critical lure, but Beato and Arndt (2021) found this effect with lists weakly related to the critical lure. Namely, higher false memories were reported in the dominant than in the non-dominant language in both adults and children, and with DRM lists that had high and low associative strength between the studied words and the critical lure.

Second, a study showed higher false recognition in L2 than L1 (Anastasi et al., 2005, Experiment 2). In this case, we can consider the L2 as the dominant language, since most of the participants frequently used this language at work (75\%) and with friends 
TABLE 1 | Summary of the reviewed studies on the role of language proficiency in false recognition.

\begin{tabular}{|c|c|c|c|c|c|c|c|c|c|}
\hline \multirow{2}{*}{\multicolumn{2}{|c|}{ Authors, year }} & \multicolumn{2}{|c|}{ Languages } & \multicolumn{2}{|r|}{ Participants } & \multirow[t]{2}{*}{ Language proficiency and background } & \multicolumn{3}{|c|}{ Results: false recognition } \\
\hline & & L1 & L2 & No. & Age $(M)$ & & L1 & L2 & Conclusion \\
\hline \multirow{3}{*}{\multicolumn{2}{|c|}{ Kawasaki-Miyaji et al., 2003}} & Japanese & English & 74 & University students (N/A) & L1: dominant language & $0.71^{1}$ & $0.62^{1}$ & $\mathrm{~L} 1>\mathrm{L} 2^{2}$ \\
\hline & & & & & & L2: 7 years of academic training & & & \\
\hline & & & & & & Participants lived in Japan & & & \\
\hline \multirow[t]{12}{*}{ Anastasi et al., 2005} & \multirow[t]{3}{*}{ Exp 1} & \multirow{3}{*}{$\begin{array}{l}\text { Japanese, } \\
\text { Spanish, } \\
\text { German }\end{array}$} & English & 12 & University students (N/A) & L1: dominant language & 0.55 & 0.49 & $\mathrm{~L} 1=\mathrm{L} 2^{3}$ \\
\hline & & & & & & L2: 8.51 years of experience/academic training & & & \\
\hline & & & & & & $\begin{array}{l}\text { Participants were exchange students in the } \\
\text { United States }\end{array}$ & & & \\
\hline & \multirow[t]{3}{*}{ Exp 2} & \multirow[t]{3}{*}{ Spanish } & English & 22 & Young adults (30.70) & $\begin{array}{l}\text { L1: } 75 \% \text { at home, } 45 \% \text { at work, and } 60 \% \\
\text { with friends }\end{array}$ & 0.52 & 0.70 & $\mathrm{~L} 1<\mathrm{L}^{3}$ \\
\hline & & & & & & $\begin{array}{l}\text { L2 (dominant language): } 50 \% \text { at home, } 75 \% \text { at } \\
\text { work, and } 80 \% \text { with friends }{ }^{4}\end{array}$ & & & \\
\hline & & & & & & Participants lived in the United States & & & \\
\hline & \multirow[t]{3}{*}{ Exp 3} & \multirow[t]{3}{*}{ Spanish } & \multirow[t]{3}{*}{ English } & \multirow[t]{3}{*}{20} & \multirow[t]{3}{*}{ Young adults (29.70) } & $\begin{array}{l}\text { L1 (dominant language): } 100 \% \text { at home, work, and } \\
\text { with friends }\end{array}$ & 0.59 & 0.44 & $\mathrm{~L} 1>\mathrm{L} 2^{3}$ \\
\hline & & & & & & L2: living in an L2 speaking country & & & \\
\hline & & & & & & Participants lived in the United States & & & \\
\hline & \multirow[t]{3}{*}{ Exp 4} & \multirow[t]{3}{*}{ English } & \multirow[t]{3}{*}{ Spanish } & \multirow[t]{3}{*}{24} & \multirow[t]{3}{*}{ University students (N/A) } & $\begin{array}{l}\text { L1 (dominant language): } 100 \% \text { at home, work, and } \\
\text { with friends }\end{array}$ & 0.68 & 0.16 & $\mathrm{~L} 1>\mathrm{L} 2^{3}$ \\
\hline & & & & & & L2: no formal instruction & & & \\
\hline & & & & & & Participants lived in the United States & & & \\
\hline \multirow{2}{*}{\multicolumn{2}{|c|}{ Cabeza and Lennartson, 2005}} & \multirow[t]{2}{*}{ English } & \multirow[t]{2}{*}{ French } & \multirow[t]{2}{*}{30} & \multirow[t]{2}{*}{ University students (N/A) } & $\begin{array}{l}\text { L1 and L2: high proficiency and used in } \\
\text { everyday life }\end{array}$ & 0.41 & 0.40 & $\mathrm{~L} 1=\mathrm{L} 2$ \\
\hline & & & & & & Participants lived in Canada & & & \\
\hline \multirow{3}{*}{\multicolumn{2}{|c|}{ Sahlin et al., 2005}} & \multirow[t]{3}{*}{ English } & \multirow[t]{3}{*}{ Spanish } & \multirow[t]{3}{*}{20} & \multirow[t]{3}{*}{ University students (20.00) } & $\begin{array}{l}\mathrm{L} 1 \text { (dominant language): proficiency } \\
\text { self-report }=5 / 5\end{array}$ & $0.75^{5}$ & $0.62^{5}$ & $\mathrm{~L} 1>\mathrm{L} 2^{3}$ \\
\hline & & & & & & L2: proficiency self-report = 4.55/5 & & & \\
\hline & & & & & & Participants lived in the United States & & & \\
\hline Howe et al., 2008 & & English & French & 40 & 6 years old & L1 (children and adults): dominant language & $0.74^{1}$ & $0.61^{1}$ & $\mathrm{~L} 1$ > L2 \\
\hline & & & & 32 & 8 years old & L2 (children): L2-immersion school. & & & \\
\hline & & & & 30 & 12 years old & This was the only L2-speaking environment & & & \\
\hline & & & & 20 & 20 years old & $\begin{array}{l}\text { L2 (adults): participants were formally studying } \\
\text { French }\end{array}$ & & & \\
\hline & & & & & & All lived in an L1 community in Canada & & & \\
\hline
\end{tabular}


TABLE 1 | Continued

\begin{tabular}{|c|c|c|c|c|c|c|c|c|c|}
\hline \multirow[t]{2}{*}{ Authors, year } & & \multicolumn{2}{|c|}{ Languages } & \multicolumn{2}{|r|}{ Participants } & \multirow[t]{2}{*}{ Language proficiency and background } & \multicolumn{3}{|c|}{ Results: false recognition } \\
\hline & & L1 & L2 & No. & Age $(M)$ & & L1 & L2 & Conclusion \\
\hline \multirow[t]{3}{*}{ Marmolejo et al., 2009} & & English & Spanish & 60 & University students (20.63) & $\begin{array}{l}\text { L1 (dominant language): proficiency } \\
\text { self-report }=9.35 / 10\end{array}$ & 0.80 & 0.73 & $\mathrm{~L} 1>\mathrm{L}^{2}$ \\
\hline & & & & & & L2: proficiency self-report $=8.40 / 10$ & & & \\
\hline & & & & & & Participants lived in the United States & & & \\
\hline \multirow[t]{10}{*}{ Arndt and Beato, 2017} & Exp 1 & English & Spanish & 28 & University students (19.75) & L1: dominant language & 0.29 & 0.15 & $\mathrm{~L} 1>\mathrm{L} 2$ \\
\hline & & & & & & $\begin{array}{l}\text { L2: participants were formally studying a third-term } \\
\text { Spanish course. Proficiency self-report }=6.32 / 10\end{array}$ & & & \\
\hline & & & & & & Participants lived in the United States & & & \\
\hline & $\operatorname{Exp} 2$ & Spanish & English & 156 & University students (22.48) & L1: dominant language & 0.30 & 0.14 & $\mathrm{~L} 1>\mathrm{L} 2$ \\
\hline & & & & & & $\begin{array}{l}\text { L2: studied on primary and secondary school. } \\
\text { Proficiency self-report }=5.25 / 10\end{array}$ & & & \\
\hline & & & & & & Participants lived in Spain & & & \\
\hline & Exp 3 & Spanish & English & 52 & University students (25.69) & L1: dominant language & 0.35 & 0.18 & $\mathrm{~L} 1>\mathrm{L} 2$ \\
\hline & & & & & & $\begin{array}{l}\text { L2: participants were formally studying English, } 26 \\
\text { at elementary (low) level and } 26 \text { at advanced (high) } \\
\text { level. }\end{array}$ & & $\begin{array}{l}\text { High: } 0.22 \\
\text { Low: } 0.13\end{array}$ & High > Low \\
\hline & & & & & & Proficiency self-report: low $=4.31 / 10$, high $=7 / 10$ & & & \\
\hline & & & & & & Participants lived in Spain & & & \\
\hline \multirow[t]{5}{*}{ Beato and Arndt, 2021} & Exp 1 & Spanish & English & 90 & University students (21.76) & L1: dominant language & 0.33 & 0.21 & $\mathrm{~L} 1>\mathrm{L} 2$ \\
\hline & & & & & & $\begin{array}{l}\text { L2: studied on primary and secondary school. } \\
\text { Proficiency self-report }=6.02 / 10\end{array}$ & & & \\
\hline & & & & & & Participants lived in Spain & & & \\
\hline & $\operatorname{Exp} 2$ & Spanish & English & 164 & Young adults (29.69) & L1: dominant language & 0.28 & 0.16 & $\mathrm{~L} 1>\mathrm{L} 2$ \\
\hline & & & & & & $\begin{array}{l}\text { L2: participants were formally studying English, } 58 \\
\text { at elementary (low) level, } 59 \text { intermediate (mid) level, } \\
\text { and } 47 \text { advanced (high) level. Proficiency } \\
\text { self-report: low }=5.36 / 10, \text { mid }=6.54 / 10 \text {, } \\
\text { high }=6.89 / 10 \\
\text { Participants lived in Spain }\end{array}$ & & $\begin{array}{l}\text { High: } 0.19 \\
\text { Mid: } 0.12 \\
\text { Low: } 0.12\end{array}$ & $\begin{array}{l}\text { High }>\text { Mid } \\
\text { High }>\text { Low } \\
\text { Mid }=\text { Low }\end{array}$ \\
\hline
\end{tabular}

False recognition rates are reported as mean proportions. $L 1$, first language; $L 2$, second language; $N / A$, not available.

${ }^{1}$ Means were provided by the first author in Kawasaki-Miyaji et al. (2003) and estimated form Figure 4 in Howe et al. (2008).

${ }^{2}$ The comparison was not tested statistically.

${ }^{3}$ Analyses were conducted on corrected scores in Anastasi et al. (2005) and sensitivity scores in Sahlin et al. (2005).

${ }^{4}$ Some participants reported using both languages in various environments.

${ }^{5}$ Only means for the first study-test trial are reported to be comparable to the other studies. 
$(80 \%)$, and even half of participants used it at home. Therefore, here we can also conclude that false memories were higher in the dominant than in the non-dominant language.

Third, we identified two studies where false recognition was similar in the L1 and L2 (Anastasi et al., 2005, Experiment 1; Cabeza and Lennartson, 2005). In these cases, L1 and L2 proficiency seem to be similar. Specifically, Cabeza and Lennartson (2005) reported highly proficient speakers that used both languages in everyday life with no dominance difference specified. For their part, Anastasi et al. (2005, Experiment 1) included participants whose dominant language seems to be the L1, but it is also important to consider that participants had several years of L2 academic training, besides living in the L2-speaking country. As L2 acquisition and its associated brain changes are highly related to the amount of L2 immersion (Pliatsikas et al., 2017), it is reasonable to think that, in this case, participants could reach high levels of L1 and L2 proficiency at the moment of testing. Thus, in these two studies, we would expect false recognition not to differ significantly between $\mathrm{L} 1$ and L2 (since L1 and L2 proficiency would be similar), and this was exactly the result found in both experiments.

Lastly, two studies investigated false memories in participants that differed in L2 proficiency (Arndt and Beato, 2017; Beato and Arndt, 2021). Specifically, the authors found that greater language proficiency in the non-dominant language increased false memories. This result is in line with the above reported greater false recognition in the dominant (high proficiency, in these studies) than in the non-dominant (low proficiency, in these studies) language.

\section{DISCUSSION}

The reviewed studies suggest that, regardless of age and the associative strength of the lists, false memories are higher in participants' dominant language than in their non-dominant one, just as false memories are greater in high than low L2 proficiency participants. Only when proficiency in the L1 and L2 is similar, false memories do not differ. These results could be accommodated by theoretical accounts from very different research areas, false memory and bilingual language processing.

Regarding the theoretical framework of the false memory effect, both the AMF and the FFT, mentioned above, could explain the current data despite claiming different mechanisms underlying the effect. On the one hand, according to FFT, the extraction of gist representations improves throughout development because participants become better in processing word meaning and connecting meaning across different words (Brainerd and Reyna, 2002). Given the parallel between how false memory differ across the proficiency continuum and the developmental trajectory of false memory (e.g., Carneiro and Fernandez, 2010; Arndt and Beato, 2017), this prediction can be used to explain the present results. That is, gist memory would be hindered when processing L2-words as participants have less experience, leading to a decrease in false memories. Along the same lines, gist memory improves when participants become more proficient, explaining why high L2 proficiency speakers show greater false memories than low L2 proficiency speakers. On the other hand, the activation processes referred by the AMF could explain the findings reviewed above by arguing that concepts are more automatically activated by the dominant than the non-dominant language, or even by high L2-proficiency participants. This activation spread throughout a well-organized network with strong connections to associatively related words (i.e., critical lure), which in turn would produce higher false memories in the dominant language than in the non-dominant one, as well as in high rather than low L2 proficiency speakers.

Within the bilingual language processing research, the greater false memories in the dominant than non-dominant language (e.g., Sahlin et al., 2005) could be accommodated by the RHM (e.g., Kroll and Stewart, 1994) since this model proposes stronger conceptual links in L1 than in L2. Furthermore, this model also assumes that the conceptual links in the L1 and L2 would have similar strength if proficiency in both languages is similar, predicting that false memories will not differ between L1 and L2 (e.g., Cabeza and Lennartson, 2005). Finally, as L2 proficiency increases, this theory suggests that the links between L2 words and their concepts strengthened, which predicts higher false memories for higher L2 proficiency participants (e.g., Arndt and Beato, 2017). With an increase in L2 proficiency as a function of language usage (Heredia, 1997), the L2 can even come to be the dominant language, in this case expecting higher false recognition in L2 than in L1 (e.g., Anastasi et al., 2005, Experiment 2).

In conclusion, this review has demonstrated that the DRM paradigm is useful to deepen our understanding of language and memory processes in speakers with knowledge of more than one language. Moreover, this review highlights the importance of language dominance to understand the production of false memories in the L1 and the L2. Therefore, we believe that it is crucial to assess language proficiency and exhaustively report participants' language backgrounds on research that included more than one language. To do so some questionnaires have been created (e.g., Li et al., 2006; Marian et al., 2007; Luk and Bialystok, 2013; Anderson et al., 2018) that might be useful for future research. Additionally, as previous works showed that participants had far from perfect knowledge of L2 stimuli (Beato and Arndt, 2021), we encourage researchers to evaluate L2 word knowledge within future studies to assess the validity of alternative explanations for memory effects.

After reviewing the available articles investigating false memories in L1 versus L2, an issue that still seems unclear is whether participants translated L2 words during task performance (see Graves and Altarriba, 2014). Thus, further research could clarify this issue by manipulating the presentation rate of studied items or the time available during retrieval. Furthermore, researchers interested in measuring brain electrical activity need to describe the neural correlates of false recognition in the L1 and the L2 as, to our knowledge, no previous research has examined this matter. Additionally, it would be interesting to know whether false memories in the DRM paradigm differ between monolinguals and bilinguals. Although this issue is beyond the scope of this review, it would add valuable information to our understanding of language and memory processes in bilingual speakers. 


\section{AUTHOR CONTRIBUTIONS}

Both authors listed have made a substantial, direct and intellectual contribution to the work, and approved it for publication.

\section{REFERENCES}

Abe, N., Fujii, T., Suzuki, M., Ueno, A., Shigemune, Y., Mugikura, S., et al. (2013). Encoding- and retrieval-related brain activity underlying false recognition. Neurosci. Res. 76, 240-250. doi: 10.1016/j.neures.2013.05.006

Aizpurua, A., Garcia-Bajos, E., and Migueles, M. (2009). False memories for a robbery in young and older adults. Appl. Cogn. Psychol. 23, 174-187. doi: $10.1002 / \mathrm{acp}$

Albuquerque, P. B. (2005). Produção de evocações e reconhecimentos falsos em 100 listas de palavras associadas portuguesas [False recall and recognition production in 100 Portuguese associate word list]. Lab. Psicol. 3, 3-12. doi: 10.14417/lp.766

Anastasi, J. S., Rhodes, M. G., Marquez, S., and Velino, V. (2005). The incidence of false memories in native and non-native speakers. Memory 13, 815-828. doi: 10.1080/09658210444000421

Anderson, J. A. E., Mak, L., Keyvani Chahi, A., and Bialystok, E. (2018). The language and social background questionnaire: assessing degree of bilingualism in a diverse population. Behav. Res. Methods 50, 250-263. doi: 10.3758/s13428017-0867-9

Arndt, J. (2010). The role of memory activation in creating false memories of encoding context. J. Exp. Psychol. Learn. Mem. Cogn. 36, 66-79. doi: 10.1037/ a0017394

Arndt, J. (2012). The influence of forward and backward associative strength on false recognition. J. Exp. Psychol. Learn. Mem. Cogn. 38, 747-756. doi: 10.1037/ a0026375

Arndt, J. (2015). The influence of forward and backward associative strength on false memories for encoding context. Memory 23, 1093-1111. doi: 10.1080/ 09658211.2014 .959527

Arndt, J., and Beato, M. S. (2017). The role of language proficiency in producing false memories. J. Mem. Lang. 95, 146-158. doi: 10.1016/j.jml.2017.03.004

Arndt, J., and Hirshman, E. (1998). True and false recognition in MINERVA2: explanations from a global matching perspective. J. Mem. Lang. 39, 371-391. doi: 10.1006/jmla.1998.2581

Beato, M. S., and Arndt, J. (2014). False recognition production indexes in forward associative strength (FAS) lists with three critical words. Psicothema 26, 457463. doi: 10.7334/psicothema2014.79

Beato, M. S., and Arndt, J. (2017). The role of backward associative strength in false recognition of DRM lists with multiple critical words. Psicothema 29, 358-363. doi: 10.7334 psicothema2016.248

Beato, M. S., and Arndt, J. (2021). The effect of language proficiency and associative strength on false memory. Psychol. Res. [Epub ahead of print] doi: 10.1007/ s00426-020-01449-3

Beato, M. S., Boldini, A., and Cadavid, S. (2012). False memory and level of processing effect: an event-related potential study. NeuroReport 23, 804-808. doi: 10.1097/WNR.0b013e32835734de

Beato, M. S., and Cadavid, S. (2016). Normative study of theme identifiability: instructions with and without explanation of the false memory effect. Behav. Res. Methods 48, 1252-1265. doi: 10.3758/s13428-015-0652-6

Beato, M. S., and Díez, E. (2011). False recognition production indexes in Spanish for 60 DRM lists with three critical words. Behav. Res. Methods 43, 499-507. doi: 10.3758/s13428-010-0045-9

Bhatt, R., Laws, K. R., and McKenna, P. J. (2010). False memory in schizophrenia patients with and without delusions. Psychiatry Res. 178, 260-265. doi: 10.1016/ j.psychres.2009.02.006

Bialystok, E., Dey, A., Sullivan, M. D., and Sommers, M. S. (2020). Using the DRM paradigm to assess language processing in monolinguals and bilinguals. Mem. Cogn. 48, 870-883. doi: 10.3758/s13421-020-01016-6

Boldini, A., Beato, M. S., and Cadavid, S. (2013). Modality-match effect in false recognition: an event-related potential study. NeuroReport 24, 108-113. doi: 10.1097/WNR.0b013e32835c93e3

\section{FUNDING}

This work was partially supported by grant SA052G18, Junta de Castilla y León, and by the University of Salamanca.

Bookbinder, S. H., and Brainerd, C. J. (2016). Emotion and false memory: the context-content paradox. Psychol. Bull. 142, 1315-1351. doi: 10.1037/ bul0000077

Brainerd, C. J., and Reyna, V. F. (2002). Fuzzy-trace theory and false memory. Curr. Direct. Psychol. Sci. 11, 164-169. doi: 10.1111/1467-8721.00192

Brainerd, C. J., Reyna, V. F., and Ceci, S. J. (2008). Developmental reversals in false memory: a review of data and theory. Psychol. Bull. 134, 343-382. doi: 10.1037/0033-2909.134.3.343

Brainerd, C. J., Reyna, V. F., Wright, R., and Mojardin, A. H. (2003). Recollection rejection: false-memory editing in children and adults. Psychol. Rev. 110, 762-784. doi: 10.1037/0033-295X.110.4.762

Brainerd, C. J., and Wright, R. (2005). Forward association, backward association, and the false-memory Illusion. J. Exp. Psychol. Learn. Mem. Cogn. 31, 554-567. doi: 10.1037/0278-7393.31.3.554

Brysbaert, M., and Duyck, W. (2010). Is it time to leave behind the revised hierarchical model of bilingual language processing after fifteen years of service? Bilingual. Lang. Cogn. 13, 359-371. doi: 10.1017/S1366728909990344

Cabeza, R., and Lennartson, E. R. (2005). False memory across languages: implicit associative response vs fuzzy trace views. Memory 13, 1-5. doi: 10.1080/ 09658210344000161

Cadavid, S., and Beato, M. S. (2016). Memory distortion and its avoidance: an event-related potentials study on false recognition and correct rejection. PLoS One 11:e0164024. doi: 10.1371/journal.pone.0164024

Carneiro, P., Albuquerque, P., Fernandez, A., and Esteves, F. (2007). Analyzing false memories in children with associative lists specific for their age. Child Dev. 78, 1171-1185. doi: 10.1111/j.1467-8624.2007.01059.x

Carneiro, P., and Fernandez, A. (2010). Age differences in the rejection of false memories: the effects of giving warning instructions and slowing the presentation rate. J. Exp. Child Psychol. 105, 81-97. doi: 10.1016/j.jecp.2009.09. 004

Carneiro, P., Fernandez, A., and Dias, A. R. (2009). The influence of theme identifiability on false memories: evidence for age-dependent opposite effects. Mem. Cogn. 37, 115-129. doi: 10.3758/MC.37.2.115

Carneiro, P., Garcia-Marques, L., Fernandez, A., and Albuquerque, P. (2014). Both associative activation and thematic extraction count, but thematic false memories are more easily rejected. Memory 22, 1024-1040. doi: 10.1080/ 09658211.2013.864680

Chang, M., Brainerd, C. J., Toglia, M. P., and Schmidt, S. R. (2020). Norms for emotion-false memory lists. Behav. Res. Methods 53, 96-112. doi: 10.3758/ s13428-020-01410-7

Chen, J. C. W., Li, W., Westerberg, C. E., and Tzeng, O. J.-L. (2008). Test-item sequence affects false memory formation: an event-related potential study. Neurosci. Lett. 431, 51-56. doi: 10.1016/j.neulet.2007.11.020

Coane, J. H., Huff, M. J., and Hutchison, K. A. (2016). The ironic effect of guessing: increased false memory for mediated lists in younger and older adults. Aging Neuropsychol. Cogn. 23, 282-303. doi: 10.1080/13825585.2015.108 8506

Curran, T., Schacter, D. L., Johnson, M. K., and Spinks, R. (2001). Brain potentials reflect behavioral differences in true and false recognition. J. Cogn. Neurosci. 13, 201-216. doi: 10.1162/089892901564261

Deese, J. (1959). On the prediction of occurrence of particular verbal intrusions in immediate recall. J. Exp. Psychol. 58, 17-22. doi: 10.1037/h0046671

Devitt, A. L., and Schacter, D. L. (2016). False memories with age: neural and cognitive underpinnings. Neuropsychologia 91, 346-359. doi: 10.1016/j. neuropsychologia.2016.08.030

Díez, E., Gómez-Ariza, C. J., Díez-Álamo, A. M., Alonso, M. A., and Fernandez A. (2017). The processing of semantic relatedness in the brain: evidence from associative and categorical false recognition effects following transcranial direct current stimulation of the left anterior temporal lobe. Cortex 93, 133-145. doi: 10.1016/j.cortex.2017.05.004 
Dijkstra, T., and Van Heuven, W. J. B. (2002). The architecture of the bilingual word recognition system: from identification to decision. Bilingual. Lang. Cogn. 5, 175-197. doi: 10.1017/s1366728902003012

Dubuisson, J. B., Fiori, N., and Nicolas, S. (2012). Repetition and spacing effects on true and false recognition in the DRM paradigm. Scand. J. Psychol. 53, 382-389. doi: 10.1111/j.1467-9450.2012.00963.x

Edwards, J. (2004). "Foundations of bilingualism," in The Handbook of Bilingualism, eds T. K. Bhatia and W. C. Ritchie (Hoboken, NJ: Blackwell Publishing), 7-31.

Favre, G., Horat, S. K., Herrmann, F. R., Gothuey, I., Ventura, J., Merlo, M. C. G., et al. (2020). False memory production in schizophrenia: a neurophysiological investigation. Schizophren. Res. Cogn. 20, 100174-100179. doi: 10.1016/j.scog. 2020.100174

Flegal, K. E., and Reuter-Lorenz, P. A. (2014). Get the gist? The effects of processing depth on false recognition in short-term and long-term memory. Mem. Cogn. 42, 701-711. doi: 10.3758/s13421-013-0391-9

Francis, W. S. (1999). Cognitive integration of language and memory in bilinguals: semantic representation. Psychol. Bull. 125, 193-222. doi: 10.1037/0033-2909. 125.2.193

Francis, W. S. (2020). Shared core meanings and shared associations in bilingual semantic memory: evidence from research on implicit memory. Int. J. Bilingual. 24, 464-477. doi: 10.1177/1367006918814375

Francis, W. S., Strobach, E. N., Penalver, R. M., Martínez, M., Gurrola, B. V., and Soltero, A. (2019). Word-context associations in episodic memory are learned at the conceptual level: word frequency, bilingual proficiency, and bilingual status effects on source memory. J. Exp. Psychol. Learn. Mem. Cogn. 45, 1852-1871. doi: $10.1037 / \mathrm{xlm} 0000678$

Gallo, D. A. (2006). Associative Illusions of Memory: False Memory Research in DRM and Related Tasks. Hove: Psychology Press.

Gallo, D. A. (2010). False memories and fantastic beliefs: 15 years of the DRM illusion. Mem. Cogn. 38, 833-848. doi: 10.3758/MC.38.7.833

Giammattei, J., and Arndt, J. (2012). Hemispheric asymmetries in the activation and monitoring of memory errors. Brain Cogn. 80, 7-14. doi: 10.1016/j.bandc. 2012.04.003

Gollan, T. H., Montoya, R. I., Cera, C., and Sandoval, T. C. (2008). More use almost always means a smaller frequency effect: aging, bilingualism, and the weaker links hypothesis. J. Mem. Lang. 58, 787-814. doi: 10.1016/j.jml.2007.07.001

Graves, D. F., and Altarriba, J. (2014). "False memories in bilingual speakers," in Foundations of Bilingual Memory, eds R. R. Heredia and J. Altarriba (Berlin: Springer), 205-221.

Green, D. W. (1998). Mental control of the bilingual lexico-semantic system. Bilingual. Lang. Cogn. 1, 67-81. doi: 10.1017/s1366728998000133

Havard, C., and Memon, A. (2013). The mystery man can help reduce false identification for child witnesses: evidence from video line-ups. Appl. Cogn. Psychol. 27, 50-59. doi: 10.1002/acp.2870

Hellenthal, M. V., Knott, L. M., Howe, M. L., Wilkinson, S., and Shah, D. (2019). The effects of arousal and attention on emotional false memory formation. J. Mem. Lang. 107, 54-68. doi: 10.1016/j.jml.2019.03.010

Heredia, R. R. (1997). Bilingual memory and hierarchical models: a case for language dominance. Curr. Direct. Psychol. Sci. 6, 34-39. doi: 10.1111/14678721.ep11512617

Heredia, R. R., and Altarriba, J. (2001). Bilingual language mixing: why do bilinguals code-switch? Curr. Direct. Psychol. Sci. 10, 164-168. doi: 10.1111/ 1467-8721.00140

Heredia, R. R., and Brown, J. M. (2006). "Bilingual memory," in The Handbook of Bilingualism, eds T. K. Bhatia and W. C. Ritchie (Hoboken, NJ: Blackwell Publishing), 225-249.

Howe, M. L., and Akhtar, S. (2020). Priming older adults and people with mild to moderate Alzheimer's disease problem-solving with false memories. Cortex 125, 318-331. doi: 10.1016/j.cortex.2020.01.014

Howe, M. L., Gagnon, N., and Thouas, L. (2008). Development of false memories in bilingual children and adults. J. Mem. Lang. 58, 669-681. doi: 10.1016/j.jml. 2007.09.001

Huff, M. J., Bodner, G. E., and Fawcett, J. M. (2015). Effects of distinctive encoding on correct and false memory: a meta-analytic review of costs and benefits and their origins in the DRM paradigm. Psychon. Bull. Rev. 22, 349-365. doi: 10.3758/s13423-014-0648-8
Huff, M. J., Bodner, G. E., and Gretz, M. R. (2020). Reducing false recognition in the Deese-Roediger/McDermott paradigm: related lures reveal how distinctive encoding improves encoding and monitoring processes. Front. Psychol. 11:602347. doi: 10.3389/fpsyg.2020.602347

Kawasaki, Y., and Yama, H. (2006). The difference between implicit and explicit associative processes at study in creating false memory in the DRM paradigm. Memory 14, 68-78. doi: 10.1080/09658210444000520

Kawasaki-Miyaji, Y., Inoue, T., and Yama, H. (2003). Cross-linguistic false recognition: how do japanese-dominant bilinguals process two languages: Japanese and English? Psychologia 46, 255-267. doi: 10.2117/psysoc.2003.255

Knott, L. M., Howe, M. L., Wimmer, M. C., and Dewhurst, S. A. (2011). The development of automatic and controlled inhibitory retrieval processes in true and false recall. J. Exp. Child Psychol. 109, 91-108. doi: 10.1016/j.jecp.2011.01. 001

Kolodner, J. L. (1983). Reconstructive memory: a computer model. Cogn. Sci. 7 , 281-328. doi: 10.1016/S0364-0213(83)80002-0

Kroll, J. F., Michael, E., Tokowicz, N., and Dufour, R. (2002). The development of lexical fluency in a second language. Sec. Lang. Res. 18, 137-171. doi: 10.1191/ 0267658302sr201oa

Kroll, J. F., and Stewart, E. (1994). Category interference in translation and picture naming: evidence for asymmetric connections between bilingual memory representations. J. Mem. Lang. 33, 149-174. doi: 10.1006/jmla.1994.1008

Kroll, J. F., Van Hell, J. G., Tokowicz, N., and Green, D. W. (2010). The revised hierarchical model: a critical review and assessment. Bilingual. Lang. Cogn. 13, 373-381. doi: 10.1017/S136672891000009X

Kubota, Y., Toichi, M., Shimizu, M., Mason, R. A., Findling, R. L., Yamamoto, K., et al. (2006). Prefrontal hemodynamic activity predicts false memory-A near-infrared spectroscopy study. NeuroImage 31, 1783-1789. doi: 10.1016/j. neuroimage.2006.02.003

Li, P., Sepanski, S., and Zhao, X. (2006). Language history questionnaire: a Webbased interface for bilingual research. Behav. Res. Methods 38, 202-210. doi: $10.3758 / \mathrm{BF} 03192770$

Loftus, E. F. (2018). Eyewitness science and the legal system. Annu. Rev. Law Soc. Sci. 14, 1-10. doi: 10.1146/annurev-lawsocsci-101317-030850

Luk, G., and Bialystok, E. (2013). Bilingualism is not a categorical variable: interaction between language proficiency and usage. J. Cogn. Psychol. 25, 605-621. doi: 10.1080/20445911.2013.795574

Malone, C., Deason, R. G., Palumbo, R., Heyworth, N., Tat, M., and Budson, A. E. (2019). False memories in patients with mild cognitive impairment and mild Alzheimer's disease dementia: can cognitive strategies help? J. Clin. Exp. Neuropsychol. 41, 204-218. doi: 10.1080/13803395.2018.1513453

Mao, W. B., Yang, Z. L., and Wang, L. S. (2010). Modality effect in false recognition: evidence from Chinese characters. Int. J. Psychol. 45, 4-11. doi: 10.1080/ 00207590902757641

Marian, V., Blumenfeld, H. K., and Kaushanskaya, M. (2007). The Language Experience and Proficiency Questionnaire (LEAP-Q): assessing language profiles in bilinguals and multilinguals. J. Speech Lang. Hear. Res. 50, 940-967. doi: 10.1044/1092-4388(2007/067)

Marmolejo, G., Deliberto-Macaluso, K. A., and Altarriba, J. (2009). False memory in bilinguals: does switching languages increase false memories? Am. J. Psychol. $122,1-16$.

McCabe, D. P., Roediger, H. L., McDaniel, M. A., and Balota, D. A. (2009). Aging reduces veridical remembering but increases false remembering: neuropsychological test correlates of remember-know judgments. Neuropsychologia 47, 2164-2173. doi: 10.1016/j.neuropsychologia.2008.11.025

Nelson, D. L., McEvoy, C. L., and Schreiber, T. A. (1998). The University of South Florida word association, rhyme, and word fragment norms. Behav. Res. Methods Instru. Comp. 36, 402-407.

Neuschatz, J. S., Benoit, G. E., and Payne, D. G. (2003). Effective warnings in the Deese-Roediger-McDermott false-memory paradigm: the role of identifiability. J. Exp. Psychol. Learn. Mem. Cogn. 29, 35-41. doi: 10.1037/0278-7393.29.1.35

Otgaar, H., Muris, P., Howe, M. L., and Merckelbach, H. (2017). What drives false memories in psychopathology? A case for associative activation. Clin. Psychol. Sci. 5, 1048-1069. doi: 10.1177/2167702617724424

Otgaar, H., Peters, M., and Howe, M. L. (2012). Dividing attention lowers children's but increases adults' false memories. J. Exp. Psychol. Learn. Mem. Cogn. 38, 204-210. doi: 10.1037/a0025160 
Perea, M., Duñabeitia, J. A., and Carreiras, M. (2008). Masked associative/semantic priming effects across languages with highly proficient bilinguals. J. Mem. Lang. 58, 916-930. doi: 10.1016/j.jml.2008.01.003

Pérez-Mata, M. N., Read, J. D., and Diges, M. (2002). Effects of divided attention and word concreteness on correct recall and false memory reports. Memory 10 , 161-177. doi: 10.1080/09658210143000308

Pliatsikas, C., DeLuca, V., Moschopoulou, E., and Saddy, J. D. (2017). Immersive bilingualism reshapes the core of the brain. Brain Struct. Funct. 222, 1785-1795. doi: 10.1007/s00429-016-1307-9

Reyna, V. F., and Brainerd, C. J. (1995). Fuzzy-trace theory: an interim synthesis. Learn. Indiv. Differ. 7, 1-75. doi: 10.1016/1041-6080(95)90031-4

Roediger, H. L., and McDermott, K. B. (1995). Creating false memories: remembering words not presented in lists. J. Exp. Psychol. Learn. Mem. Cogn. 21, 803-814. doi: 10.1037/0278-7393.21.4.803

Roediger, H. L., Watson, J. M., McDermott, K. B., and Gallo, D. A. (2001). Factors that determine false recall: a multiple regression analysis. Psychon. Bull. Rev. 8, 385-407. doi: 10.3758/BF03196177

Sadler, D. D., Sodmont, S. M., and Keefer, L. A. (2018). Can false memory for critical lures occur without conscious awareness of list words? Conscious. Cogn. 58, 136-157. doi: 10.1016/j.concog.2017.10.018

Sahlin, B. H., Harding, M. G., and Seamon, J. G. (2005). When do false memories cross language boundaries in English-Spanish bilinguals? Mem. Cogn. 33, 1414-1421. doi: 10.3758/BF03193374

Schacter, D. L., Reiman, E., Curran, T., Yun, L. S., Bandy, D., McDermott, K. B., et al. (1996). Neuroanatomical correlates of veridical and illusory recognition memory: evidence from positron emission tomography. Neuron 17, 267-274. doi: 10.1016/S0896-6273(00)80158-0

Schacter, D. L., and Slotnick, S. D. (2004). The cognitive neuroscience of memory distortion. Neuron 44, 149-160. doi: 10.1016/j.neuron.2004.08.017

Seamon, J. G., Luo, C. R., and Gallo, D. A. (1998). Creating false memories of words with or without recognition of list items: evidence for nonconscious processes. Psychol. Sci. 9, 20-26. doi: 10.1111/1467-9280.00004

Smith, T. A., and Kimball, D. R. (2012). Revisiting the rise and fall of false recall: presentation rate effects depend on retention interval. Memory 20, 535-553. doi: 10.1080/09658211.2012.684881

Stadler, M. A., Roediger, H. L., and McDermott, K. B. (1999). Norms for word lists that create false memories. Mem. Cogn. 27, 494-500. doi: 10.3758/BF032 11543
Surrain, S., and Luk, G. (2019). Describing bilinguals: a systematic review of labels and descriptions used in the literature between 20052015. Bilingual. Lang. Cogn. 22, 401-415. doi: 10.1017/S13667289170 00682

Turk, K. W., Palumbo, R., Deason, R. G., Marin, A., Elshaar, A., Gosselin, E., et al. (2020). False memories: the other side of forgetting. J. Int. Neuropsychol. Soc. 26, 545-556. doi: 10.1017/S1355617720000016

Ulatowska, J., and Olszewska, J. (2013). Creating associative memory distortionsa Polish adaptation of the DRM paradigm. Polish Psychol. Bull. 44, 449-456. doi: $10.2478 /$ ppb-2013-0048

Van Damme, I., and d'Ydewalle, G. (2009). Implicit false memory in the DRM paradigm: effects of amnesia, encoding instructions, and encoding duration. Neuropsychology 23, 635-648. doi: 10.1037/a0016017

Van Hell, J. G., and De Groot, A. M. B. (1998). Conceptual representation in bilingual memory: effects of concreteness and cognate status in word association. Bilingual. Lang. Cogn. 1, 193-211. doi: 10.1017/ s1366728998000352

Watson, J. M., McDermott, K. B., and Balota, D. A. (2004). Attempting to avoid false memories in the Deese/Roediger-McDermott paradigm: assessing the combined influence of practice and warnings in young and old adults. Mem. Cogn. 32, 135-141. doi: 10.3758/BF03195826

Wojcik, D. Z., Díez, E., Alonso, M. A., Martín-Cilleros, M. V., GuisuragaFernández, Z., Fernández, M., et al. (2018). Diminished false memory in adults with autism spectrum disorder: evidence of identify-to-reject mechanism impairment. Res. Aut. Spect. Disord. 45, 51-57. doi: 10.1016/j.rasd.2017. 11.001

Conflict of Interest: The authors declare that the research was conducted in the absence of any commercial or financial relationships that could be construed as a potential conflict of interest.

Copyright (c) 2021 Suarez and Beato. This is an open-access article distributed under the terms of the Creative Commons Attribution License (CC BY). The use, distribution or reproduction in other forums is permitted, provided the original author(s) and the copyright owner(s) are credited and that the original publication in this journal is cited, in accordance with accepted academic practice. No use, distribution or reproduction is permitted which does not comply with these terms. 